\title{
LAS CALAVERAS DE CONCHA DE EK' BALAM
}

\author{
THE SHELL SKULLS FROM EK’ BALAM
}

\author{
Leticia Vargas De la Peña ${ }^{1}$ \\ ekbalam.lvp@gmail.com / Orcid https://0000-0003-3277-5663 \\ Víctor R. Castillo Borges ${ }^{1}$ \\ muyjoochak@gmail.com / Orcid https://0000-0003-4861-5701 \\ Cristian A. Hernández González ${ }^{2}$ \\ arqueologomaya@gmail.com / Orcid https://0000-0002-9879-1933
}

\section{RESUMEN}

El presente artículo da a conocer los resultados del análisis tipológico y taxonómico realizado a 13 pendientes de concha con forma de calaveras, provenientes del palacio real de Ek' Balam, conocido como la Acrópolis. Las piezas formaron parte de la ofrenda mortuoria del rey Ukit Kan Lek Tok', iniciador de la dinastía gobernante en el reino de Talol, durante el Clásico tardío (770 d.C.-Ca. 896 d.C). Se presentan datos generales del sitio arqueológico, una breve descripción del contexto en que fueron halladas las piezas, así como del hallazgo de la tumba real y su rica ofrenda. Se exponen los resultados de los análisis técnicos realizados, de la identificación biológica de la malacofauna presente en Ek' Balam, su procedencia y las técnicas de manufactura empleadas en la elaboración de los pendientes. Como complemento se mencionan hallazgos similares reportados en otros sitios prehispánicos y se aborda - aunque someramente - el simbolismo de estas piezas en el territorio Mesoamericano y especialmente en el palacio real de Ek' Balam.

Palabras clave: Concha; pendientes; calaveras; simbología.

\footnotetext{
${ }^{1}$ Investigadora del Instituto Nacional de Antropología e Historia, Centro Yucatán, México.

2 Investigador del Proyecto Ek' Balam, del Instituto Nacional de Antropología e Historia, , México.
} 


\section{ABSTRACT}

This article make known the results of the typological and taxonomic analysis carried out on 13 skull-shaped shell pendants from the royal palace of Ek' Balam, known as the Acropolis. The pieces were part of the mortuary offering of King Ukit Kan Lek Tok', initiator of the ruling dynasty in the kingdom of Talol, during the Late Classic (770 A.C.Ca. 896 A.C). General data of the archaeological site are presented, a brief description of the context in which the pieces were found, as well as the discovery of the royal tomb and its rich offering. Also, the results of the technical analyses carried out, the biological identification of malacofauna present in Ek' Balam, its origin and the manufacturing techniques used in the elaboration of the pendants. Similar findings reported on other preHispanic sites are mentioned and, in addition, the symbolism of these pieces - this topic is briefly addressed - in Mesoamerican territory and especially in the royal palace of Ek' Batam.

Keywords: Shell; pendants; skulls; symbology.

\section{CONTEXTO DE LA INVESTIGACIÓN}

La obtención, producción, consumo y uso de objetos elaborados con conchas de moluscos han sido ampliamente documentados en diversos sitios arqueológicos a lo largo y ancho de Mesoamérica, así como en algunos sitios del norte de México, los artículos son de temática diversa y especies muy variadas.

En el proyecto "Técnicas de manufactura de los objetos de concha del Méxíco prehispánico" desarrollado desde el año 1997 por el Dr. Adrián Velázquez Castro y sus colaboradores en el Museo del Templo Mayor del INAH, el estudio de las huellas dejadas por las distintas herramientas y los materiales, así como la comparación de rasgos de los materiales arqueológicos, ha permitido inferir las técnicas utilizadas por distintas sociedades del México prehispánico 
(VELÁZQUEZ, 2006: 45) sus estudios han ampliado enormemente los análisis malacológicos, pero también los de las técnicas de trabajo y las herramientas utilizadas, desarrollando la arqueología experimental y dando nuevas luces en el conocimiento de las sociedades mesoamericanas.

Análisis malacológicos hay muchos, pero hasta donde hemos podido observar, son pocos los que han reportado objetos de concha en forma de calaveras, no obstante ser bastante comunes los elaborados con caracoles del género Oliva, con trabajos muy parecidos entre sí, aunque también hay otros casos de diferentes características, pero podríamos decir que se trata de ejemplos aislados.

Los singulares pendientes de concha encontrados en Ek' Balam y especialmente los que formaron parte del rico ajuar funerario del rey Ukit Kan Lek Tok' destacan por la maestría y detalle con que fueron creados, así como por la especial particularidad de algunos de ellos, de estar conformados por piezas móviles.

El hallazgo de la tumba de este gobernante se suscitó en el año 2000 y fue una sorpresa que su rica ofrenda funeraria haya consistido principalmente de piezas de concha y caracol, más que de jade y otros materiales. La mayoría de las piezas son pendientes y otras joyas personales del gobernante, aunados a otra gran cantidad de diversos objetos y de variada materia prima que completan una abundante $y$ original ofrenda. 
Desde el hallazgo todos los objetos fueron debidamente registrados, pero no fue posible ir más allá por falta de recursos, aunque era evidente la necesidad de efectuar estudios específicos en ellos. En el caso de los elementos malacológicos, fue hasta el año 2012 cuando finalmente hubo presupuesto para iniciar un análisis formal. Esta investigación sigue su curso, aunque lentamente y con interrupciones fuera de nuestro control.

Algunas de las piezas más singulares de la ofrenda mortuoria son los pendientes de concha en forma de calaveras. Algunos de estos ornamentos se destacan por las especies de conchas de moluscos con las que fueron elaboradas — como es el caso de la Pinctada mazatlanica, de la provincia malacológica del Pacífico- así como por las técnicas empleadas para su manufactura y sus características y diseños tan insólitos.

También existen otros ejemplares muy interesantes, que aunque no forman parte de la ofrenda del ajaw, fueron recuperados en diversas partes de su palacio real en Ek' Balam y los incluimos en este estudio, por tratarse de elementos semejantes a los de la tumba.

Este trabajo da a conocer los resultados del análisis tipológico y taxonómico realizado a 13 pendientes con forma de calaveras, provenientes de la Acrópolis de Ek’ Balam. 
Como referencia, mencionamos hallazgos similares reportados en otros sitios prehispánicos y abordamos - aunque someramente- el simbolismo de estas piezas en el territorio Mesoamericano y en el palacio real de Ek’ Balam.

Para poner en contexto las piezas motivo de este estudio, primeramente, se da a conocer información relativa al asentamiento maya, señalando su ubicación y los datos más relevantes, del sitio y de su edificio principal, identificado como el palacio real y el lugar donde se ubica el mausoleo del gobernante. Tratando específicamente de los pendientes de concha, exponemos los resultados del análisis tipológico y taxonómico de cada uno de los objetos en cuestión, las técnicas de manufactura ejecutadas por los artesanos prehispánicos y el origen biológico de las conchas y caracoles utilizados para elaborar las calaveras.

Consideramos importante abordar el simbolismo de las calaveras, un tema constante en la ornamentación de Ek' Balam ya que, través de la interpretación de estas piezas, podemos aproximarnos a la cosmovisión e ideología de los habitantes del sitio.

\section{EK' BALAM Y}

Ek’ Balam está situado en la planicie norte del estado mexicano de Yucatán, cincuenta kilómetros al noreste de Chichén Itzá y sesenta kilómetros al noroeste de Cobá, equidistante entre las poblaciones modernas de Valladolid al sur y Tizimín al norte. Ek’ Balam es un sitio ya conocido desde la época Colonial, pues 
formó parte de una encomienda. En sus "ruinas" se construyó una capilla abierta colonial; en las Relaciones Histórico-Geográficas de la Gobernación de Yucatán, de la segunda mitad del siglo XVI, hay mención de sus edificios, esculturas e incluso sus inscripciones (DE LA GARZA et al., 2008).

El Centro ANAH Yucatán inició los trabajos de investigación y restauración de la parte nuclear de Ek’ Balam en 1994 y a partir de 1997 las labores se centraron en el mayor edificio del sitio, que simplemente por su ubicación — presidiendo la parte septentrional de la Plaza Norte - y sus grandes dimensiones, evidenciaba su importancia. Después de varias temporadas de trabajo de campo, gracias a los hallazgøs realizados se pudo identificar este edificio como el palacio real, que fue construido principalmente por el ajaw Ukit Kan Lek Tok', quien fue el iniciador de la dinastía gobernante en el Clásico tardío-terminal (770 d. C.-Ca. 869 d.C.).

Luego de múltiples e importantes hallazgos en este singular edificio, se llegó a uno de los más relevantes, la fachada zoomorfa o teratomorfa llamada la Sak Xok Naaj "La casa blanca de la lectura" un recinto que fue edificado por dicho gobernante en el ala oeste del Cuarto Nivel de la Acrópolis (LACADENA, 2003). Esta fue la obra máxima de este gobernante, no sólo por su aspecto y por su contenido, sino especialmente por su función, que en la época prehispánica le asignó dicho nombre, como consta en la tapa de bóveda pintada hallada en el interior. 
Ya estando en el proceso de exploración de la fachada de este edificio, fue hallada la tumba de Ukit Kan Lek Tok' en el año 2000, en una cámara mortuoria construida en el interior del recinto posterior al de la fachada tan ricamente decorada. El ajaw utilizó en vida este especial recinto para realizar reuniones con tos escribas y sabios del reino y a su muerte se convirtió en su mausoleo. La rica ofrenda mortuoria tenía más de 10,000 piezas de materiales variados, como cerámica, lítica, jade, hueso y pirita, pero el material más abundante fue la concha. La ofrenda incluía veintiuna vasijas, la mayoría de barro: cajetes, una cazuela, un gran vaso negro, una olla con tapa — bajo la que se encontraron cinco espinas de raya- y un vaso globular; cinco recipientes son de alabastro, incluyendo dos cajetes, dos vasos y un vaso-efigie (VARGAS y CASTILLO, 2001; VARGAS et al., s.f.).

Se depositaron en la tumba también 207 piezas de jade —orejeras, pendientes, cuentas tubulares y redondas, discos, pequeñas cabezas talladas - algunas, como las orejeras o las cuentas tubulares colocadas en asociación con el cuerpo, probablemente formando parte de sus adornos, otras aparentemente esparcidas por la cámara. El rico ajuar lo vinieron a completar 51 placas de pirita, tres perlas perforadas y un pendiente en forma de rana, de oro-tumbaga procedente de Centroamérica (VARGAS y CASTILLO, 2001; VARGAS et al., s.f.).

Realmente fue de llamar la atención la riqueza de la ofrenda y sus características fuera de lo común, pues las tumbas reales suelen tener principalmente una gran 
cantidad de jade y en menor cantidad, otros materiales. Pero aquí ocurrió lo contrario, la gran mayoría de las piezas son de concha, principalmente de especies locales, como las Americoliva reticularis (antes Oliva reticularis), Ollivela, Chamaflorida o Aliger gigas (antes Strombus gigas), pero también especies de la eosta del Pacífico, como la Pinctada mazatlanica o la Spondylus crassisquama (antes Spondylus prínceps). Algunas formaban grandes grupos, como las más de 5000 cuentas de caracoles pequeños (Americoliva reticularis y Olivella) que se dispusieron a la izquierda del cuerpo, o las 105 conchas talladas con forma de granos de cacao que se depositaron en el costado derecho del cuerpo. El resto de las conchas, todavía en número de varios miles, consistían en placas, cuentas y figuras talladas, muchas de ellas de extraordinaria delicadeza, presentando perforaciones que sugieren su función como colgantes o su pertenencia a diversas piezas de vestimenta o tocados. Algunas de las conchas presentaban recubrimiento de estuco y pintura roja (LACADENA et al., s.f.).

Entre las conchas talladas destacan por la calidad de su factura la que representan un pez, que además tiene una inscripción esgrafiada que lo identifica como el us Kay ("la corvina") de Ukit Kan Lek; también hay dos pendientes en forma de camarones, una cabeza de rabihorcado y un venado lamiéndose el lomo, además de las numerosas piezas talladas con perfiles de flores y otras formas diversas.

Las calaveras de concha son de las piezas más llamativas de la ofrenda mortuoria y destacan por el detalle con que se representaron las características físicas que 
tiene un cráneo real como las suturas, las cuencas de los ojos, las mandíbulas, los dientes y cada elemento que fue reproducido, pero principalmente sorprende el hecho de que tres de ellas tienen mandíbulas articuladas, lo que las hacer sobresatir y ser hasta donde sabemos, únicas.

\section{CALAVERAS DE CONCHA EN MESOAMÉRICA Y SU SIMBOLISMO.}

Exhibir cabezas y partes del cuerpo como trofeos de guerra y de triunfo sobre el enemigo, como elemento para impresionar, intimidar e infundir miedo a otros, parece ser universal y parte importante de muchas prácticas rituales. Las calaveras y otros huesos, reales o esculpidos sirvieron como reliquias de las batallas ganadas por el poderío político y militar de las élites, son símbolos como menciona Virginia E. MILLER (2007: 182-183) refiriéndose al caso de las muchas repyesentaciones de calaveras en Chichén Itzá y podemos decir que fue igual en toda la Mesoamérica prehispánica. Las figuras de calaveras en la época prehispánica eran bastante comunes, sobre todo en forma de esculturas y relieves de piedra, pero no son tan frecuentes los objetos portátiles en forma de calaveras, elaborados con otro tipo de materiales.

Entre las piezas que representan calaveras, son relativamente comunes las creadas con caracoles del género Oliva, pendientes automorfos en los que se figuran los rasgos de una calavera, generalmente con incisiones y calados formando boca, ojos y fosas nasales. 
Pero son realmente pocos los hallazgos documentados de calaveras de concha y entre los existentes, algunos desafortunadamente están descontextualizados. En el Museo Amparo de Puebla por ejemplo, se encuentra una máscara sin procedencia, con la representación esquemática de un rostro cadavérico; la investigadora Veróniea Hernández Díaz (s.f.), considera que es un pendiente, pues se observaron dos orificios para colgar, además señala que los rasgos faciales humanos sugeridos con dos horadaciones caladas en los ojos, en la boca y en el área de la nariz evocan a una calavera, más que a un rostro carnado, en particular porque la apariencia blanquecina de la concha es semejante al hueso. Uno de los pendientes de Ek' Balam que aquí se describen es semejante a esta pieza, por su representación esquemática de una calavera.

En el mismo museo se encuentran un sartal de 17 pequeñas calaveras de concha pulidas y con incisiones, que según el investigador Pablo Escalante formaron un collar y aunque se desconoce su procedencia, parecen de tradición MixtecaPuebla, aunque el investigador menciona que, en realidad las piezas podrían haber sido creadas en diferentes zonas de Mesoamérica que, durante el Posclásico, compartieron muchos rasgos estilísticos y el cráneo fue una de las imágenes más comunes para aludir a la muerte; las poblaciones mesoamericanas veían decenas o centenares de cráneos en sus plazas y así como se ensartaban los cráneos en los largueros de madera de los tzompantli, se colocaron estas piezas en un collar. Otro ejemplo muy semejante se encuentra en la sala del Golfo del Museo Nacional de Antropología, procede de la región Huasteca y son cuentas que formaron parte de

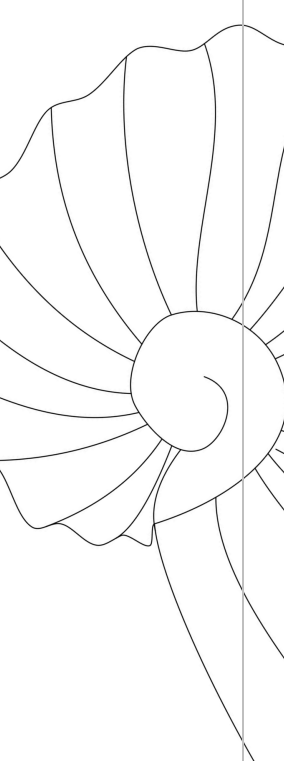


un collar, tienen forma de pequeños cráneos en bulto, son de concha y tienen un aspecto muy realista, como detalle especial se debe señalar que tienen cuentas de jade incrustadas en las cuencas de los ojos (ESCALANTE, s.f.; SUÁREZ, 2007: 91).

Estas cuentas en forma de calaveras también son muy similares a las reportadas por el Dr. Emiliano Melgar Tísoc (2007: 84S), quien registró y analizó un sartal de 20 pendientes en forma de cráneos, unos humanos y otros de primates, que fueron elaborados con caracol caribeño de la especie Aliger gigas y decorados con incrustaciones de pirita en los ojos. Estas piezas proceden del ajuar funerario localizado debajo de las escalinatas de la Pirámide de las Serpientes Emplumadas, en Xochicalco, Morelos.

A diferencia de estas piezas, las calaveras de Ek' Balam son elementos hechos para usar como pendientes, individualmente y no como parte de un sartal.

Otro hallazgo similar al registrado en Xochicalco, se dio en un salvamento arqueológico realizado al norte de la ciudad de Mérida, Yucatán, con una pieza que representa la calavera de un primate — con dos perforaciones cónicas a los costados evidenciando que se trata de un colgante- y un acanalado en la parte ventral. Esta pieza fue elaborada con la especie Aliger gigas (HERNÁNDEZ y GÓNGORA, 2011). 
La cabeza, la parte más importante de nuestra anatomía, ha recibido una especial atención y se le ha inferido un significado especial en toda la Mesoamérica prehispánica; en el imaginario cultural es el punto anímico más importante, un símbolo y también es el modelo antropomorfo de deidades y fuerzas naturales. En el ámbito universal, conservar el cráneo de algún personaje importante significa poseer el recuerdo directo de él, es apropiarse de su fuerza vital y de sus efectos benéficos. Dada su importancia simbólica en lo sagrado y el ciclo de vida, los cráneos fueron frecuentes como objetos de sacrificio, de ofrenda, como trofeos y por ello se exhibían las calaveras ya sean reales o talladas en piedra y modeladas en estuco, en diferentes escenarios, como por ejemplo en los conocidos tzompantli (ROMERO, 2013: 88; TIESLER, 2017 a: 23-25) pero también los encontramos pintados y labrados en forma de árboles, como piezas únicas y/o en conjunto, decorando frisos y otros elementos arquitectónicos y escultóricos.

Las calaveras de mandíbulas móviles halladas en Ek’ Balam pudieron simbolizar cabezas decapitadas, si las comparamos con los cráneos verdaderos colocados en los tzompantli y especialmente con un cráneo representado en un relieve de piedra del Grupo del Cementerio de Uxmal, donde "la mandíbula aparece visiblemente separada y en ambos lados del cráneo se ven los sobrantes de amarres flexibles, quizá de tela o corteza de árbol, que atraviesan las fosas cigomáticas para mantener la quijada en su lugar" (TIESLER, 2017 b: 51). De la misma manera se debieron amarrar las mandíbulas a los cráneos de los pendientes de concha y este

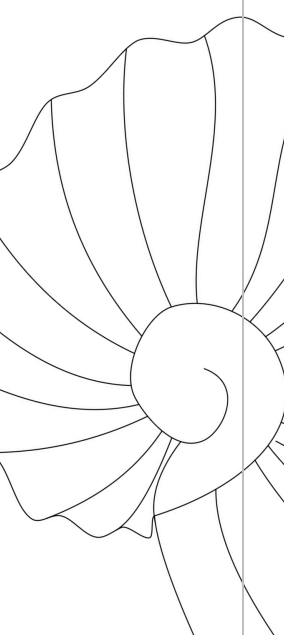


hecho debió darles un singular movimiento al estar caminando la persona que los portaba.

Existen muchas representaciones de cabezas, decapitadas o no y también de eráneos, que fueron reales como en el caso de Tenochtitlán, pero más comúnmente fueron plasmados en pinturas y esculturas, en diversos sitios como Tula, Tlatelolco, Toniná, Copán, Palenque, Mayapán, Chichén Itzá y Uxmal, entre muchos otros.

En Ek' Balam las calaveras son un tema recurrente en la iconografía, sobre todo de la Acrópolis y especialmente en forma de esculturas de piedra recubiertas con estuco modelado. En varios de los recintos del palacio real fueron halladas numerosas esculturas de piedra caliza en bulto, unas con forma de calaveras y otras mostrando seres vivos, que adornaron originalmente los frisos de varios recintos; estos elementos hacían énfasis en el tema de la vida y la muerte, como sucedió especialmente en los cuartos 23 y 33, ubicados en el Tercer Nivel del palacio real. Aunados a estos elementos tenemos tres grandes esculturas en forma de caparazones de tortugas, con personajes humanos emergiendo de ellas, recreaciones relacionadas con la idea de la resurrección. Estas esculturas decoraban originalmente el friso del Cuarto 26, ubicado en la esquina del ala oeste del Tercer Nivel de la Acrópolis. Consideramos que estas alegorías del mito de la resurrección están asociadas con las calaveras y rostros humanos vivos de los recintos aledaños ( 23 y 33 ), por lo que podemos decir que todo este sector de la 
Acrópolis estaba enfocado en el tema de la vida, la muerte y la resurrección, temas que tanto ocuparon la mente de los mayas prehispánicos (VARGAS y CASTILLO, s.f. a).

Ese especial interés en las representaciones de calaveras y la alusión a la muerte, es un rasgo muy característico de la religión mesoamericana y en particular en las expresiones artísticas. Quizá no haya otra civilización ni otro repertorio artístico en el cual las imágenes de la muerte, la presencia de cráneos, fémures, tibias, mandíbulas, así como vísceras, sea tan abundante. Este fenómeno obedece a dos hechos, por un lado se trata de una civilización agrícola, de pensamiento dualista; se piensa en la necesidad de la muerte para la vida; muerte-vida son complementarias, pues las cosas vivas mueren; se creía en la existencia de un mundo de los muertos, del cual todo retornaba para formar nueva vida (ESCALANTE s.f.). Para los mayas la muerte era parte de un ciclo y la dualidad vida-muerte era transcendental en su pensamiento y de ahí las reiteradas representaciones en su iconografía, tal como podemos ver muy claramente en Ek' Balam.

Pensamos que todos estos elementos iconográficos fueron escogidos especialmente para crear todo un escenario alrededor del lugar en el que descansaban los restos mortales del ajaw más venerado y recordado de Talol. Tras la muerte y entierro de Ukit Kan Lek Tok', su mausoleo decorado también con calaveras y seres descarnados - entre otros muchos elementos- fue ocultado por 
grandes muros, su escalera de acceso fue desmontada y el espacio que ocupaba también fue cubierto con una gran pared, donde posteriormente sería colocado un monumento de piedra registrado como Columna 1, en el que están personificados Ukit Kan Lek Tok' y uno de sus sucesores en el trono, Ukit Jol Ahkul con una representación de la tortuga del Mito de la Resurrección. Una vez oculto el mausoleo, fueron edificados nuevos recintos en el Tercer Nivel de la Acrópolis, los que ya hemos mencionado y esta es la razón de su iconografía, con la temática vida-muerte-resurrección, así como el culto a los ancestros (VARGAS y CASTLLLO s.f. b).

Las cabezas y cráneos representados en pintura y escultura de piedra y estuco son bastante comunes, pero las piezas elaboradas con otros materiales y usadas como cuentas de collares o como pendientes, son mucho más escasas. Sin embargo en Ek Balam, además de todos los elementos iconográficos relacionados con la vida y la muerte en toda la decoración del palacio real, no podían faltar dichos elementos acompañando al gobernante en su viaje al otro mundo. Y no hablamos de un elemento aislado, fueron 9 pendientes de calaveras y seguramente algunos de ellas, si no todos, habrán sido portados por Ukit Kan Lek Tok' en algún momento de su vida y por ello lo acompañaron en la muerte y en su tránsito al siguiente plano. $\mathrm{Y}$ estas piezas, seguramente a petición de él, fueron creadas con conchas y caracoles que, como sabemos - por la iconografía y materiales culturales recuperados en el palacio real y principalmente en la ofrenda mortuoria- era el material favorito de este singular gobernante.

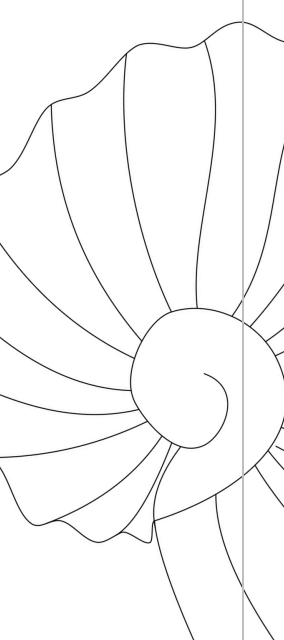




\section{LAS CALAVERAS DE CONCHA EN EK' BALAM: PROCEDENCIA Y TÉCNICAS DE MANUFACTURA}

Dentro de los resultados expuestos en la primera edición del Catálogo de los objetos de concha de Ek' Balam (HERNÁNDEZ et al., s.f.) que resume el estudio de 5925 piezas, destacan 9 exquisitos pendientes en forma de calaveras provenientes del ajuar funerario en la Tumba 1, perteneciente al rey Ukit Kan Lek Tok' y 4 pendientes más, procedentes de diversas partes de la Acrópolis o Estructura 1/del sitio, que bien pudieron ser también de su propiedad.

E\ estudio consistió en la clasificación, registro y análisis de cada una de las piezas, estableciendo categorías tipológicas de acuerdo a su forma, identificando pendientes, cuentas, broches, incrustaciones y pectorales. Para esto nos basamos en la investigación publicada por Adrián VELÁZQUEZ (1999) denominada "Tipología de los objetos de concha del Templo Mayor de Tenochtitlan" en el que identifica usos, familias (automorfa/xenomorfa), subfamilias, tipos, subtipos, grupos y variantes tipológicas en los objetos.

En una segunda fase del estudio nos dedicamos al análisis taxonómico de los objetos, que tuvo como objetivo identificar biológicamente la malacofauna presente, para esto fue necesario la consulta inicial de catálogos de moluscos del Golfo de México, Mar Caribe y del Pacífico (GARCÍA-CUBAS y REGUERO, 
2004; 2007) también de acervos digitales de los especímenes, así como de muestrarios físicos ubicados en la Malacoteca del Centro INAH Yucatán.

\section{CALAYERA 1}

Se trata de un pendiente xenomorfo, procedente de la Tumba 1 y elaborado con la especie Pinctada mazatlanica, a la que se asignó un uso votivo ornamental, por su carácter funerario. Cuenta con dos perforaciones cónicas frontales de $0.30 \mathrm{~cm}$. de diámetro y 6) perforaciones cónicas posteriores, dos en el área del cráneo de 0.25 $\mathrm{cm}$. de diámetro, dos en la mandíbula superior de $0.10 \mathrm{~cm}$. de diámetro y dos más en la mandíbula inferior, de $0.10 \mathrm{~cm}$. de diámetro. El objeto mide $6.20 \mathrm{~cm}$. de largo por $5.05 \mathrm{~cm}$. de ancho y tiene un grosor de $1.05 \mathrm{~cm}$., muestra una sutura craneal esgrafiada, 8 dientes también esgrafiados, en la mandíbula superior y 6 en la mandíbula inferior; está dividida en dos partes, por lo que se trata de una calavera de mandíbulas movibles, cuyas partes debieron estar unidas con algún tipo de cuerda (figura 1).

\section{CALAVERA 2}

Fue parte de la ofrenda mortuoria de la Tumba 1 . Mide $5.30 \mathrm{~cm}$. de largo por 4.25 $\mathrm{cm}$. de ancho y tiene un grosor de $0.50 \mathrm{~cm}$. Se trata de un pendiente xenomorfo, elaborado con la especie Triplofusus giganteus (antes Pleuroploca gigantea), que también fue de uso votivo-ornamental. Presenta dos perforaciones cónicas frontales en los ojos, de $0.55 \mathrm{~cm}$. de diámetro y además 6 perforaciones cónicas posteriores, dos están en el área del cráneo y tienen $0.15 \mathrm{~cm}$., de diámetro, dos en 
la mandíbula superior de $0.10 \mathrm{~cm}$. de diámetro y dos más en la mandíbula inferior de $0.10 \mathrm{~cm}$. de diámetro. Presenta dos pequeñas líneas esgrafiadas a modo de fosas nasales y muestra también una sutura craneal al igual, esgrafiada; con la misma técnica se representan 9 dientes en la mandíbula superior y 7 en la mandíbula inferior. Sus rasgos la colocan también dentro de la variante Mandíbulas movibles, (figura 2).

\section{CALAVERA 3}

Fue la más grande de todas, entre las procedentes de la Tumba 1; mide $6.20 \mathrm{~cm}$. de largo por $5.50 \mathrm{~cm}$. de ancho, con un grosor de $1.05 \mathrm{~cm}$. Se trata de un pendiente xenomorfo, elaborado con la especie Triplofusus giganteus; tiene dos perforaciones caladas frontales en los ojos, de $1.45 \mathrm{~cm}$. de diámetro, además 2 perforaciones cónicas frontales en el área del cráneo, de $0.30 \mathrm{~cm}$. de diámetro y por último, 2 perforaciones cónicas posteriores en el área de la mandíbula, de 0.30 $\mathrm{cm}$. de diámetro; la boca está calada, mide $2.65 \mathrm{~cm}$. de largo y muestra decoraciones esgrafiadas de 14 círculos y 13 líneas (figura 3).

\section{CALAVERA 4}

Mide $3.70 \mathrm{~cm}$. de largo por $2.71 \mathrm{~cm}$. de ancho y presenta un grosor de $0.40 \mathrm{~cm}$. Es una de las mejor ejecutadas de la muestra, por su aspecto más realista, se trata de un pendiente xenomorfo que formó parte de la ofrenda de la Tumba 1, siendo elaborado con la especie Triplofusus giganteus; ostenta dos perforaciones cónicas frontales en los ojos, de $0.60 \mathrm{~cm}$. de diámetro, 2 perforaciones cónicas frontales en 
el cráneo de $0.23 \mathrm{~cm}$. y 6 perforaciones cónicas posteriores en el área de la mandíbula de $0.10 \mathrm{~cm}$. de diámetro; cuenta con 6 dientes en la mandíbula superior, 6 en la mandíbula inferior, sutura craneal y fosas nasales esgrafiadas (figura 4).

\section{CALAVERA 5}

Mide $3.40 \mathrm{~cm}$. de largo por $2.60 \mathrm{~cm}$. de ancho y tiene un grosor de $2.20 \mathrm{~cm}$. Es un pendiente xenomorfo, igual procedente de la Tumba 1, que fue elaborado con la especie Triplofusus giganteus. Muestra ojos calados de $0.60 \mathrm{~cm}$. de diámetro y Q.25 cm., en el área central se perforaron las fosas nasales, de 0.30 y $0.35 \mathrm{~cm}$.; presenta además dos perforaciones en la mandíbula, de 0.45 y $0.41 \mathrm{~cm}$., dos perforaciones bicónicas en el área del conducto auditivo, de 0.40 y $0.45 \mathrm{~cm}$., una perforación tubular en el cráneo de $0.55 \mathrm{~cm}$. y otra bicónica de $0.60 \mathrm{~cm}$.; luce cuatro dientes superiores y la mandíbula inferior desgastada, (figura 5).

\section{CALAVERA 6}

Mide $2.55 \mathrm{~cm}$. de largo por $2.05 \mathrm{~cm}$. de ancho, con un grosor de $0.25 \mathrm{~cm}$., nuevamente se trata de un pendiente xenomorfo, procedente de la Tumba 1 , elaborado con la especie Pinctada mazatlanica; exhibe ojos calados de $0.45 \mathrm{~cm}$ y $0.50 \mathrm{~cm}$. de diámetro, también dos perforaciones cónicas frontales en el cráneo, de $0.15 \mathrm{~cm}$. y 4 perforaciones más, cónicas y posteriores, en la mandíbula, de 0.10 $\mathrm{cm}$. Es otro elemento de la variante Mandíbula movible y su diseño es muy 
similar a algunos elementos decorativos de estuco modelado que adornan la arquitectura de la Acrópolis (figura 6)

\section{CALAVERAS 7, 8 y 9}

Son pendientes automorfos de la especie Americoliva reticularis, con perforaciones cónicas que representan los ojos, fosas nasales y oídos, la boca está calada y muestra dos perforaciones caladas en la frente también. Formaron parte de la ofrenda de la Tumba 1, (figura 7).

\section{CALAVERAS 10, 11 y 12}

Son pendientes elaborados con la especie Americoliva reticularis. La número 10 muestra 8 perforaciones cónicas frontales, dos en el área de los ojos, dos en las fosas nasales, dos en el área de la boca y dos más en la sección de la barbilla, tres perforaciones caladas en su parte posterior, la boca calada y decoración esgrafiada en todo el rostro a modo de arrugas, lo que la hace aparentar un rostro anciano. La pieza número 11 tiene dos perforaciones cónicas frontales en el área de los ojos, la boca calada, las fosas nasales circulares fueron esgrafiadas; tiene además decoraciones esgrafiadas en forma de líneas horizontales, en la frente, nariz y parte superior de la boca, así como tres perforaciones cónicas posteriores. La Calavera 12 presenta tres perforaciones cónicas, dos en los ojos y una a manera de fosas nasales, la boca está calada y exhibe una decoración esgrafiada en la frente, mejillas y dientes así como tres perforaciones caladas en la sección posterior (figura 8). Las tres fueron halladas en diversas áreas de la Acrópolis.

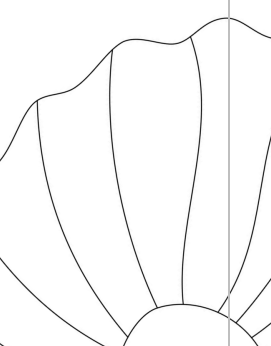




\section{CALAVERA 13}

Fue elaborada con un caracol de la especie Macrostrombus costatus (antes Strombus costatus) y es la más pequeña de todas; luce dos perforaciones bicónicas a la altura del conducto auditivo, un calado circular en la parte posterior, tres calados circulares en la sección de ojos y fosas nasales, así como una decoración esgrafiada, 7 dientes superiores y 7 dientes inferiores. Esta pieza también procede de la Acrópolis y fue recuperada durante la excavación en el ala este del Segundo Nivel, (figura 9).

\section{CONSIDERACIONES FINALES}

Las conchas de moluscos fueron altamente apreciadas en la época prehispánica, de manera primordial por el consumo alimenticio y además por su gran belleza y por su asociación con el inframundo. Este interés las hizo un objeto de comercio muy codiciado, sobre todo en los lugares alejados del mar y la mejor muestra la tenemos en las ofrendas del Templo Mayor, donde es sorprendente la cantidad y variedad de elementos de diferentes especies, que constituyeron riquezas exóticas dignas de ser ofrendadas a los dioses en un lugar tan excepcional.

Sin lugar a duda, en tiempos prehispánicos existían complejas tradiciones de explotación de los recursos marítimos, redes de distribución comercial y una producción industrial en cuanto a la necesidad de artífices especializados que desarrollaron con la práctica continua, sofisticadas tecnologías, (HERNÁNDEZ, s.f.). En Ek' Balam lo hemos comprobado claramente, hay diversas muestras de la

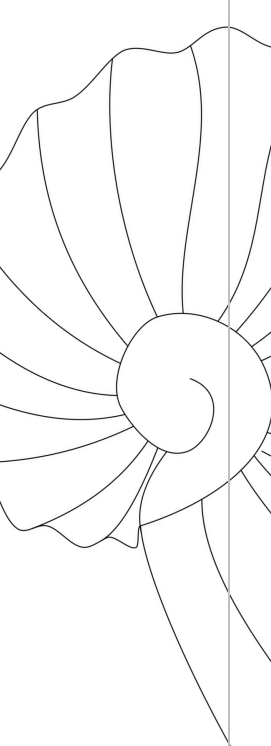


explotación de los recursos naturales en tierra y mar que podían ser obtenidos en su territorio, así como es notoria la existencia de un amplio comercio, que les permitió contar con materiales y objetos que no podían obtener en las cercanías y por supuesto, el usufructo de dichos materiales en la producción especializada de objetos de lujo y de otros materiales culturales que han sido halladas en abundancia en la que fuera la capital del reino de Talol.

La producción de objetos tan exquisitos como las calaveras de concha de Ek' Balam, elaboradas con la especie Pinctada mazatlanica, proveniente de la provincia malacológica del Pacífico, que se encuentra muy alejada de Ek' Balam, nos muestra el especial interés que tuvo la élite maya en el consumo de esta especie de concha para la elaboración de sus más preciadas piezas ornamentales, además nos habla de una amplia red comercial entre los sitios del norte de Yucatán y las regiones del Pacífico, así como con otras más cercanas. Es también un importante ejemplo del poder adquisitivo de un gobernante, que se aseguró de tener a su disposición lo mejor y más exclusivo de diversos materiales para formar parte de un ajuar que correspondiera a su importante estatus.

Tanto los gobernantes, como la gente de clase alta y aun los plebeyos usaban ornamentos de concha; en las casas prehispánicas más humildes del área maya también hemos encontrado objetos de concha, y eran tan estimados, que se colocaban como ofrenda en los enterramientos. Las conchas y caracoles estaban entre los adornos más valorados por todos, aderezando desde las más sencillas

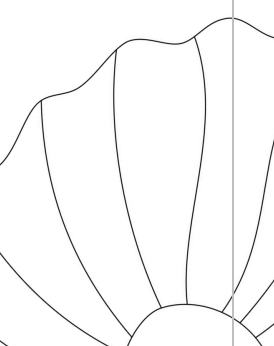


vestimentas hasta las más ricas, como parte de la compleja parafernalia de sacerdotes, guerreros y reyes que indudablemente se portaban y forjaban con mayor exquisitez. El ajuar de Ukit Kan Lek Tok' es una de las mejores muestras de la espléndida producción de objetos de concha de Ek' Balam, pero sobre todo de la especial predilección de este gobernante por los ornamentos hechos con materiales marinos, que a lo largo de su vida fueron acumulados como sus más preciadas y abundantes joyas.

Dentro de las técnicas de trabajo presentes en las calaveras, podemos observar distintos tipos de perforaciones, destacando las cónicas es las partes frontales y las acanaladas en las partes posteriores. Llaman la atención el especial detalle con que fueron creadas con elementos esgrafiados y calados. En las más realistas se muestran con volumen suficiente y con la forma perfectamente correcta anatómicamente los huesos frontales, los temporales, el arco cigomático, así como las suturas craneales, las fosas nasales y orbitales, la mandíbula -aunque separada - encaja perfectamente con el maxilar superior. Son definitivamente el resultado de una labor que sólo especialistas de tiempo completo en el trabajo de la concha pudieron haber ejecutado. Éstas son las descritas aquí como Calaveras 1,2 y 4 , (ver figuras 1,2 y 4 ).

Hay un sólo ejemplo con diseño muy esquemático y que parecería representar más una máscara, que una calavera real; la clasificamos aquí como la Calavera 3, (ver figura 3). Otro pendiente muestra detalles anatómicos menos reales, pero sus 
singularidades ciertamente los hacen muy interesantes, ésta es la Calavera 5, (ver figura 5).

Aunque hemos mencionado que las calaveras hechas con caracoles Oliva parece ser de las más comunes, igualmente fueron ejemplares muy valiosos para el gobernante, ya que fueron escogidas para formar parte de la ofrenda funeraria. Son las Calaveras 7, 8 y 9 en este trabajo, (ver figura 7).

Una pieza en particular, descrita aquí como la Calavera 6, llama la atención por su diseño igual al de algunos elementos escultóricos de la Acrópolis y nada menos que aquellos que decoran el mausoleo de Ukit Kan Lek Tok', lo que no es un parecido casual, sino que guarda relación con la temática e iconografía del edificio (ver figura 6).

Las calaveras son unas de las piezas más especiales de la ofrenda mortuoria y además de su obvio carácter funerario, refuerzan la temática recreada en varias partes del palacio real y especialmente en los niveles constructivos tercero y cuarto del edificio, donde la alegoría de vida y muerte alcanza su máxima expresión y nos revelan importantes elementos de las creencias, mitos, ritos y)el culto a los ancestros entre los mayas prehispánicos, que en Ek' Balam podemos encontrar en cada uno de los elementos decorativos y también en los ornamentos personales.

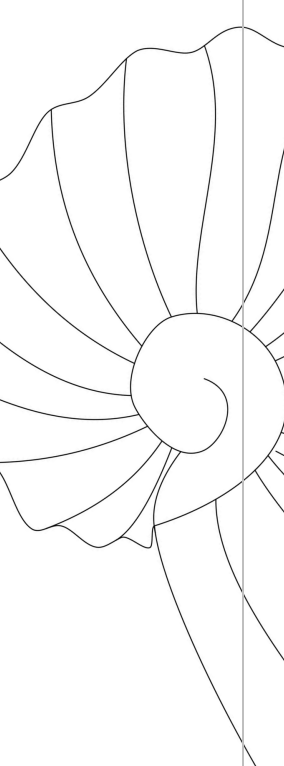


Anteriormente, en Ek' Balam se ha podido determinar la existencia de una escuela de pintores-escribas, (LACADENA et al., s.f.; VARGAS y CASTILLO, s.f. a), que difundió un estilo y técnicas hacia otros importantes sitios, como Chichén Itzá, los hallazgos en el sitio nos hacen creer que debieron existir también otras escuelas de expertos en distintas disciplinas. Ciertamente lo que ya se conoce de la arquitectura y decoración del sitio indican un alto grado de especialización de sus creadores y tratándose de la abundancia y la habilidad de los trabajos hechos con conchas de moluscos lo señalan también. Si efectivamente existió una escuela de artesanos de la concha en Ek' Balam, esperamos que las investigaciones futuras nos permitan encontrar más indicio.

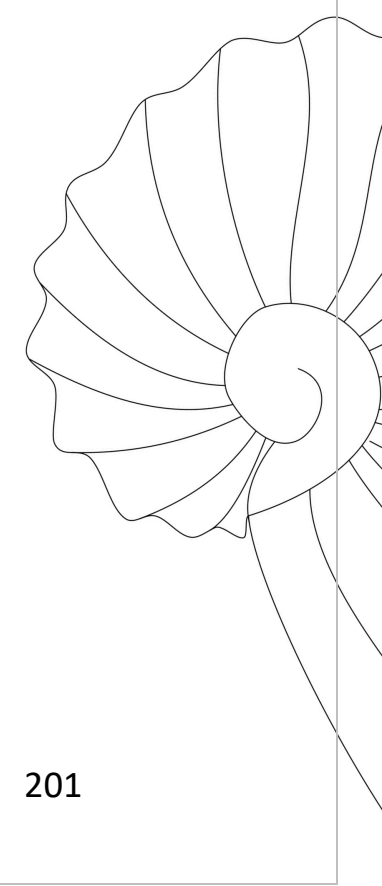




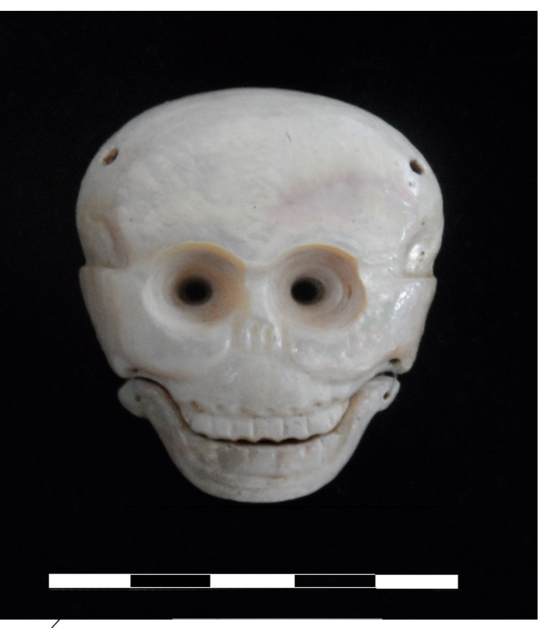

Figura 1- Calavera 1.

Figura 3- Calavera 3.

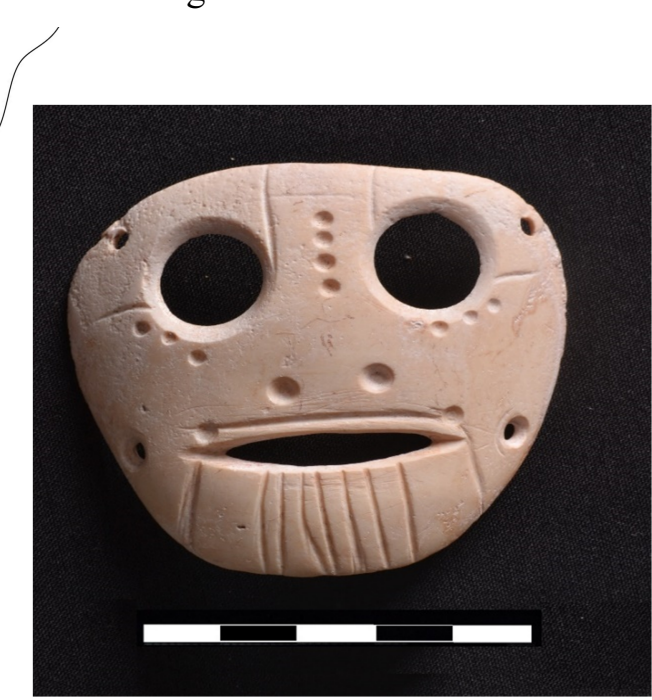

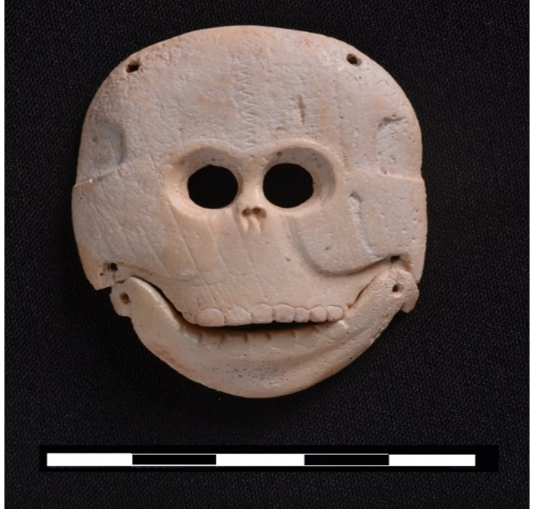

Figura 2- Calavera 2.

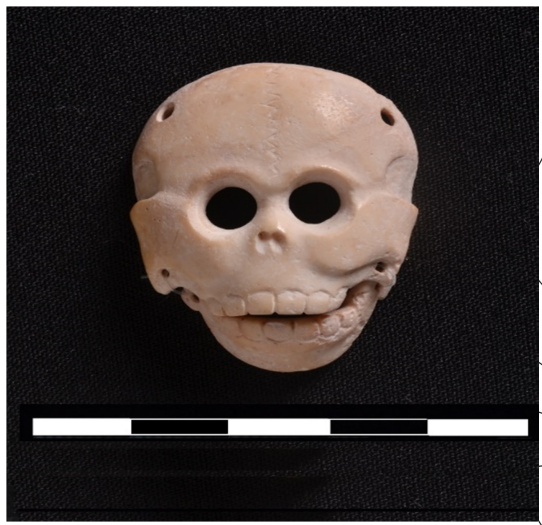

Figura 4-Calavera 4444. 


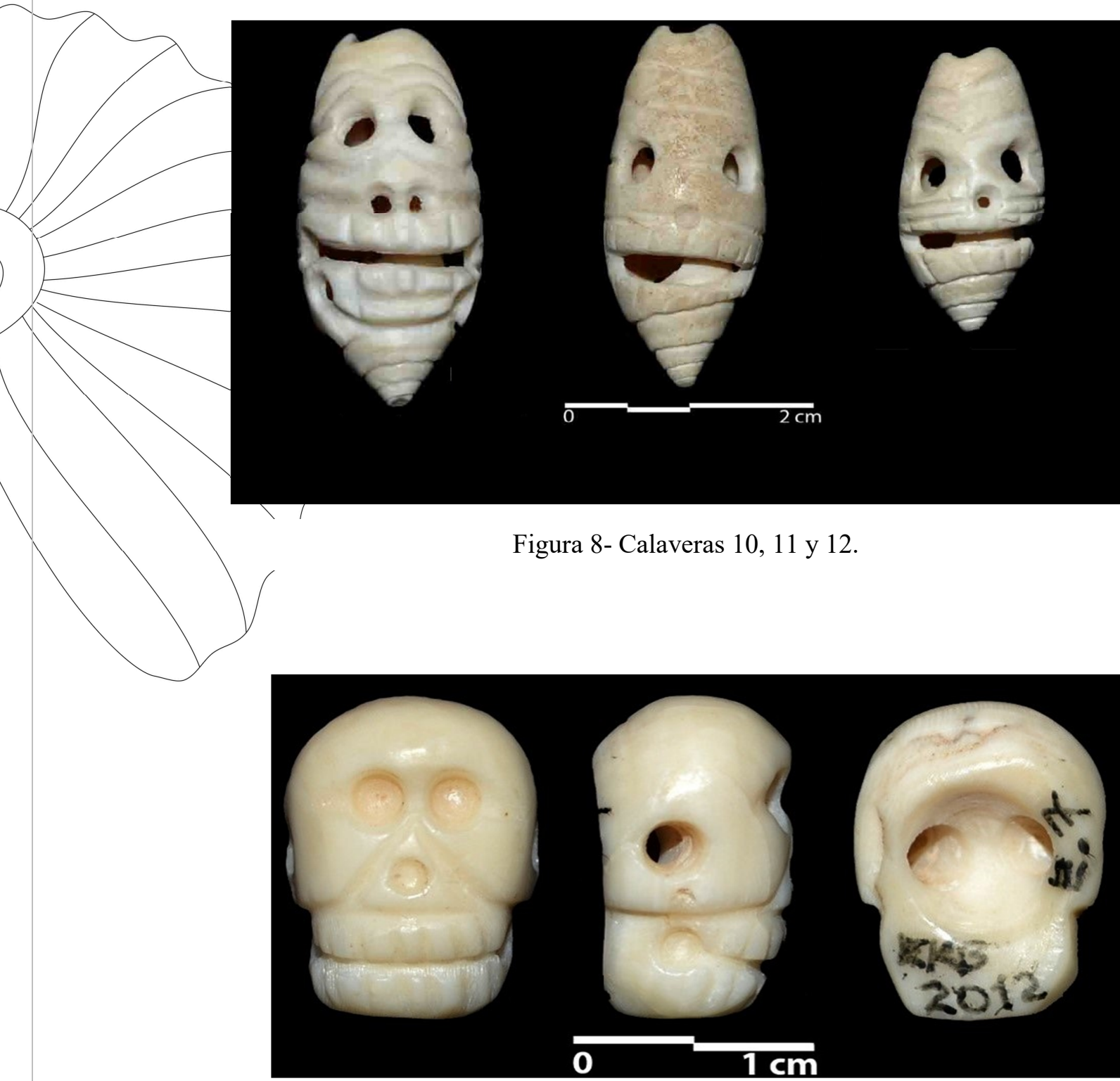

Figura 9- Calavera 13.

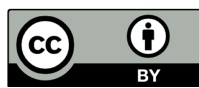




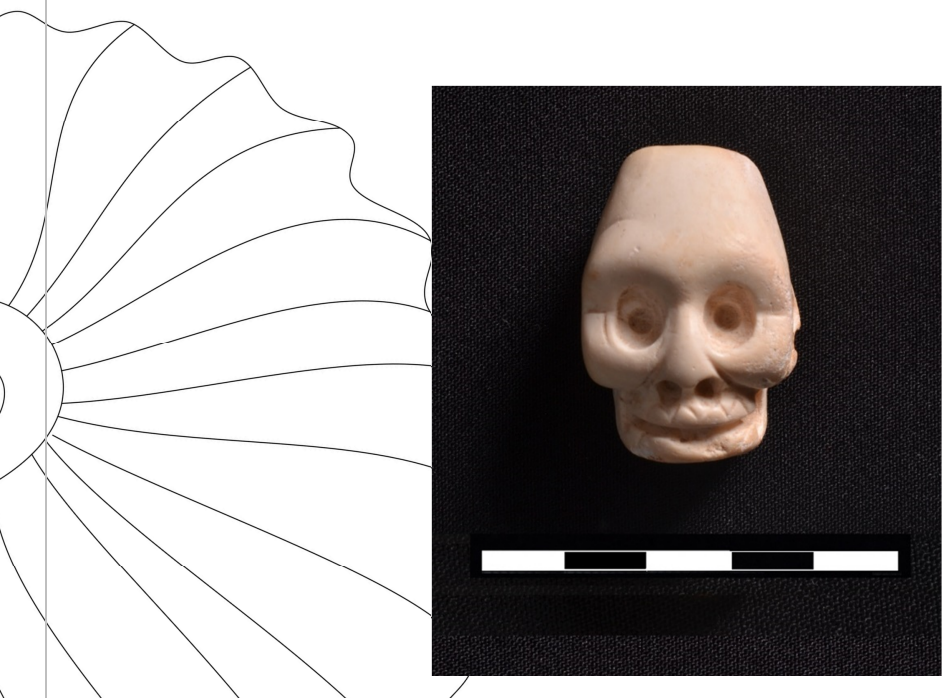

Figura 5- Calavera 5.

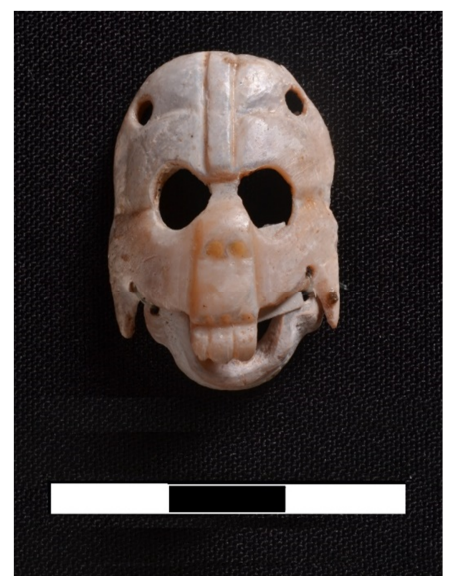

Figura 6- Calavera 6.

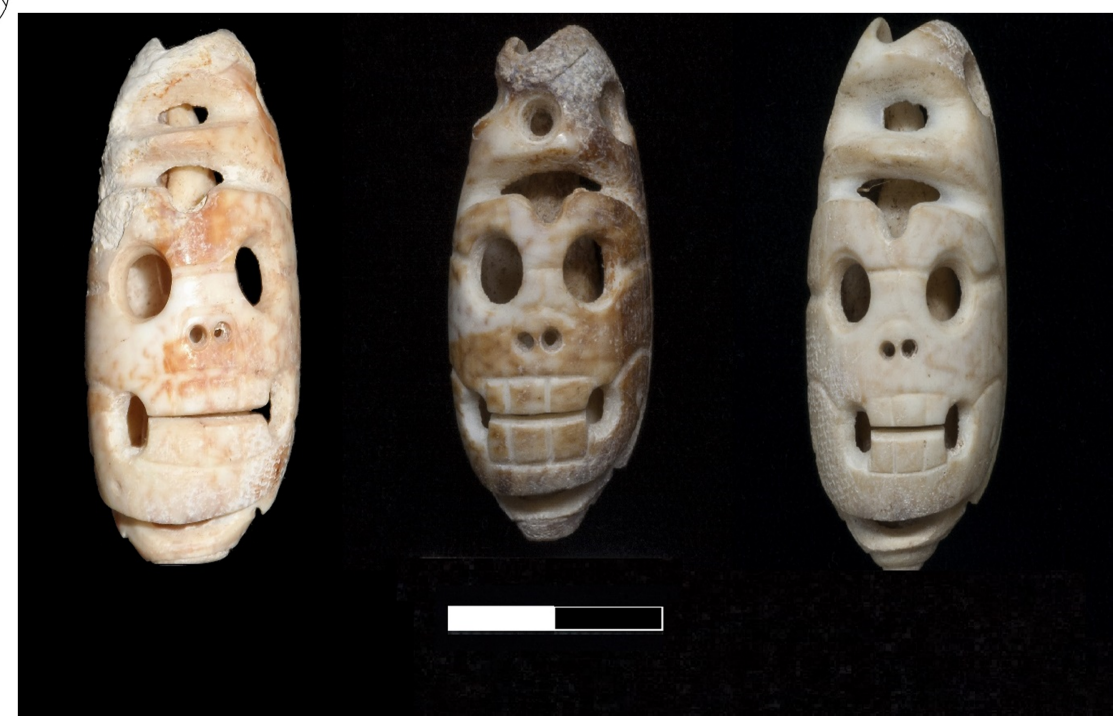

Figura 7- Calaveras 7, 8 y 9. 


\section{REFERENCIAS BIBLIOGRÁFICAS}

DE LA GARZA, M., A. L.IZQUIERDO, M. del C. LEÓN y T. FIGUEROA (eds.) 2008. Relaciones histórico-geográficas de la gobernación de Yucatán: Mérida, Valladolid y Tabasco. Tomos I y II. UNAM, México.

ESCALANTE, P. s.f. Ficha descriptiva de Collar de cráneos. Museo Amparo. Puebla, México, https://museoamparo.com/colecciones/pieza/631/collar-de-craneos?page=1

GARCÍA-CUBAS, A. y M. REGUERO. 2004. Catálogo ilustrado de moluscos gasterópodos del Golfo de México y Mar Caribe. UNAM, México.

GARCÍA-CUBAS, A. y M. REGUERO. 2007. Catálogo ilustrado de moluscos bivalvos del Golfo de México y Mar Caribe. UNAM, México.

HERNÁNDEZ, V. s.f. Ficha descriptiva de Máscara con la representación esquemática de un rostro. Museo Amparo https://museoamparo.com/colecciones/pieza/319/mascaracon-la-representacion-esquematica-de-un-rostro?page $=2$

HERNÁNDEZ, C., L. VARGAS y V. CASTILLO. s.f. Catálogo de los objetos de concha de Ek' Balam. Centro INAH Yucatán. Mérida.

HERNÁNDEZ, C. y A. GÓNGORA. 2011. Análisis tipológico y taxonómico de los artefactos de lítica y concha procedentes del Salvamento Arqueológico Comunidad Científica y Tecnológica de Yucatán. Informe Técnico, INAH. Mérida, Yucatán.

LACADENA, A. 2003. El corpus glífico de Ek’ Balam, Yucatán, México / The Glyphic Corpus of Ek' Balam, Yucatan, Mexico. Foundation for the Advancement of Mesoamerican Studies, Inc. FAMSI Reports http://www.famsi.org.

LACADENA, A., L. VARGAS y V. CASTILLO s.f. Mural Painting at Ek' Balam, Yucatan, Mexico. Paper presented at The Fourth Annual Tulane Maya Symposium. Murals and Painted Texts by Maya Ah Tzi'bob. Tulane University. February 2-4, 2007. 
MELGAR, E. 2007. Las ofrendas de concha de moluscos de la Pirámide de las Serpientes

Emplumadas, Xochicalco, Morelos, en: Revista Mexicana de Biodiversidad 78: 83S-92S, UNAM, México.

MILLER, V. E. 2007. Skeletons, Skulls, and Bones in the Art of Chichen Itza, en: V. Tiesler, y A. Cucina (eds.) New Perspectives on Human Sacrifice and Ritual Body Treatments in Ancient Maya Society. Interdisciplinary Contributions to Archaeology. Ed. Springer. U.S., 165-189.

ROMERO, R. 2013. El culto a los ancestros: cambios y continuidade”, en M. de la Garza y M. del C. Valverde (coords.), Continuidad, cambios y rupturas en la religión maya, Centro de Estudios Mayas. Instituto de Investigaciones Filológicas. UNAM, México, 7998.

SUÁREZ, 1. 2007. Conchas y caracoles ese universo maravilloso. INAH, México.

TIESLER, V. 2017 a. Simbolismo de la cabeza en Mesoamérica, en: Arqueología 206 Mexicana 148: 23-27. Editorial Raíces. México.

TIESLER, V. 2017 b. Cráneos perforados y tzompantli en Chichén Itzá, en: Arqueología Mexicana 148: 46-51. Editorial Raíces. México.

VARGAS, L. y V. CASTILLO. s.f. b. La vida y la muerte del kalo'mte' Ukit Kan Lek Tok Ponencia presentada en el IX Congreso Internacional de Mayistas. Campeche, México. 23 al 29 de junio de 2013.

VARGAS, L. y V. CASTILLO. 2001. El Mausoleo de Ukit Kan L'ek Tok en: Los Investigadores de la Cultura Maya 9. Tomo I: 144-150. Universidad Autónoma de Campeche, Campeche. México.

VELÁZQUEZ, A. 1999. Tipología de los objetos de concha del Templo Mayor de Tenochtitlán. Colección Científica, INAH, México. técnico del Consejo de Arqueología del INAH. México

VARGAS, L., V. CASTILLO, T. CEBALlOS y S. JIMÉNEZ. s.f. Proyecto de investigación y conservación arquitectónica en Ek' Balam. Informe de actividades. Temporada 1998-2000. Temporada 2001. Tomos I y II. Archivo.

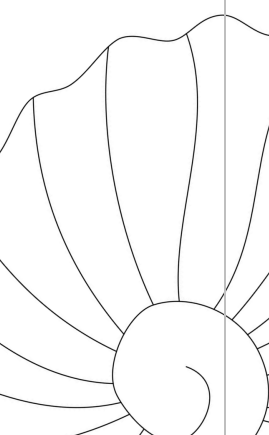

